Nat. Hazards Earth Syst. Sci., 10, 181-189, 2010

www.nat-hazards-earth-syst-sci.net/10/181/2010/

(C) Author(s) 2010. This work is distributed under

the Creative Commons Attribution 3.0 License.

\title{
Near real-time GPS applications for tsunami early warning systems
}

\author{
C. Falck ${ }^{1}$, M. Ramatschi ${ }^{1}$, C. Subarya ${ }^{2}$, M. Bartsch ${ }^{1}$, A. Merx ${ }^{1}$, J. Hoeberechts ${ }^{1}$, and G. Schmidt ${ }^{1}$ \\ ${ }^{1}$ GFZ German Research Centre for Geosciences, 14473 Potsdam, Germany \\ ${ }^{2}$ Bakosurtanal, National Coordinating Agency for Surveys and Mapping, Cibinong 16911, Indonesia
}

Received: 13 October 2009 - Revised: 22 December 2009 - Accepted: 5 January 2010 - Published: 2 February 2010

\begin{abstract}
GPS (Global Positioning System) technology is widely used for positioning applications. Many of them have high requirements with respect to precision, reliability or fast product delivery, but usually not all at the same time as it is the case for early warning applications. The tasks for the GPS-based components within the GITEWS project (German Indonesian Tsunami Early Warning System, Rudloff et al., 2009) are to support the determination of sea levels (measured onshore and offshore) and to detect co-seismic land mass displacements with the lowest possible latency (design goal: first reliable results after $5 \mathrm{~min}$ ). The completed system was designed to fulfil these tasks in near realtime, rather than for scientific research requirements. The obtained data products (movements of GPS antennas) are supporting the warning process in different ways. The measurements from GPS instruments on buoys allow the earliest possible detection or confirmation of tsunami waves on the ocean. Onshore GPS measurements are made collocated with tide gauges or seismological stations and give information about co-seismic land mass movements as recorded, e.g., during the great Sumatra-Andaman earthquake of 2004 (Subarya et al., 2006). This information is important to separate tsunami-caused sea height movements from apparent sea height changes at tide gauge locations (sensor station movement) and also as additional information about earthquakes' mechanisms, as this is an essential information to predict a tsunami (Sobolev et al., 2007).

This article gives an end-to-end overview of the GITEWS GPS-component system, from the GPS sensors (GPS receiver with GPS antenna and auxiliary systems, either onshore or offshore) to the early warning centre displays. We describe how the GPS sensors have been installed, how they are operated and the methods used to collect, transfer and
\end{abstract}

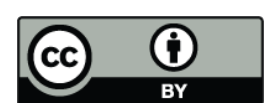

Correspondence to: C. Falck (falck@gfz-potsdam.de) process the GPS data in near real-time. This includes the sensor system design, the communication system layout with real-time data streaming, the data processing strategy and the final products of the GPS-based early warning system components.

\section{Introduction}

In 2005 the German government initiated the GITEWS project as a reaction to the disastrous Indian Ocean tsunami of 26 December 2004. After the final handover all GITEWS system components will be operated by Indonesian partner institutions. Some components of the early warning system are based on GNSS-technology (Global Navigation Satellite System) using signals from Global Positioning System GPS. The geodetic branch of the GFZ, German Research Centre for Geosciences has a strong background in the operation of geodetic sensor networks including data processing and the development of task and environment adapted sensor stations. Many GPS measurement campaigns, with site surveys in Indonesia, were undertaken by GFZ for the GEODYSSEA project until 1998 (Wilson and Michel, 1998). All these points were important for GITEWS and resulted in newly designed GPS sensor networks covering landsides, coastal areas and open sea locations and a new near real-time data processing and monitoring system. Other tsunami early warning concepts as, e.g., at the PTWC (Pacific Tsunami Warning Center) use partly similar sensors like the DART buoys (Deep-ocean Assessment and Reporting of Tsunamis, Meinig et al., 2005), but without GPSbased components. The implementation of GPS-based components (among other innovations) into InaTEWS (Indonesian Tsunami Early Warning System) makes an important difference to earlier tsunami warning concepts.

Published by Copernicus Publications on behalf of the European Geosciences Union. 


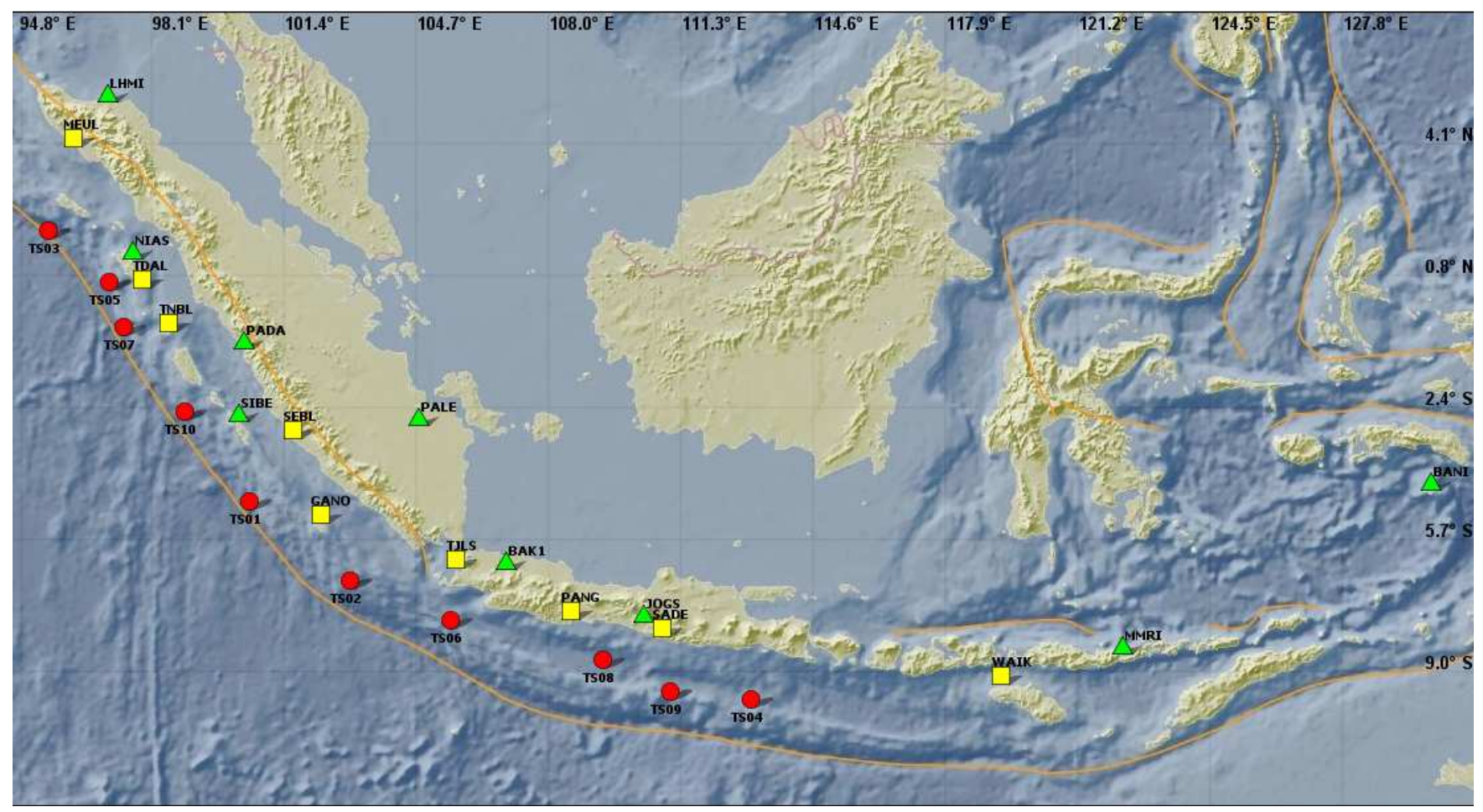

Fig. 1. GITEWS GPS locations in Indonesia [numbers in squared brackets indicate installation status of December 2009]: 9 [7] GPS real-time reference stations (green triangles), 9 [9] GPS at tide gauges (yellow squares), 10 [8] buoys with GPS (red circles).

\section{GPS sensor systems for early warning systems}

There are four groups of GPS sensor systems utilised by GITEWS. Three of the groups have been developed within GITEWS for their special tasks (real-time reference, tide gauge collocated, offshore measurement). The locations in Indonesia equipped with GITEWS GPS instrumentation are shown in Fig. 1. The fourth group of sensors contains external GPS stations, e.g., as being part of the global IGS (International GNSS Service) network. The latter group is not necessary for the early warning tasks but provides a tie to a global reference frame. The first group of stations is the GPS real-time reference stations (GPS RTR), which are distributed over the main islands of Indonesia, mostly in the inland and collocated with seismological installations. They detect ground movements and provide an internal reference frame for other GITEWS GPS sensors. The second group of GPS sensors are collocated at tide gauge stations along coast lines. The third GPS sensor group is installed on buoys, which are anchored at open sea locations. All GITEWS GPS sensor stations utilise geodetic type dual frequency GPS/GNSS receivers (e.g., Septentrio PolaRx2 and PolaRx3, Topcon Net-G3) with choke ring antennas, meteo-sensors (Vaisala) and low power consumption computers (PC 104 standard). The types of GPS receiver and antenna are considered to be of minor importance (within the indicated class of equipment). All sensor stations use VSAT (Very Small Aper- ture Terminal) or BGAN (Broadband Global Area Network) as primary satellite communication system, which proved to perform well when properly installed. Most stations have a BGAN or IRIDIUM (low Earth orbit satellite system for mobile phone communication) system for backup or to allow failure recovery. The differences between the sensor station designs are due to the different fields of operation with subsequent different power supply, primary communication and operation concepts (see Table 1). One difference is the data transfer concept. Buoys and tide gauge stations operate with file-based data collection (one file per $10 \mathrm{~min}$ ) and data transfer in intervals of some hours. Real-time reference stations permanently stream data with $1 \mathrm{~Hz}$ and collect the data in backup files, which are only used to fill gaps after temporary communication outages. GPS observations of all sensor station types are collected and transferred as raw observation data in binary format.

\subsection{GPS RTR (Real-Time Reference) stations}

The GPS RTR network provides reference stations for baseline mode processing of GPS sensor data from buoys and at tide gauges. Each GPS RTR station sends a GPS data stream in real-time at a data rate of $1 \mathrm{~Hz}$, meteorological $(5 \mathrm{~min})$ and housekeeping data $(1 \mathrm{~min})$. The data are transmitted via a permanent VSAT satellite link and received through the VSAT hub at the warning centre in Jakarta. Coordinate time 
Table 1. Sensor groups (types) being used by the GITEWS GPS-based early warning system.

\begin{tabular}{|c|c|c|c|}
\hline Sensor group & Targets/functions & Data transmission/communication & Sample rate \\
\hline GPS@RTR & $\begin{array}{l}\text { - ground motion detection } \\
\text { - reference sites for GPS@Buoy } \\
\text { (differential data processing) }\end{array}$ & $\begin{array}{l}\text { - real-time data streaming and } \\
\text { file-based (15-min files) data transmission } \\
\text { - permanent VSAT satellite link }\end{array}$ & $1 \mathrm{~Hz}$ \\
\hline GPS@tide gauge & $\begin{array}{l}\text { - ground motion detection } \\
\text { - tide gauge data flagging or correction }\end{array}$ & $\begin{array}{l}\text { - normal mode: variable intervals, file-based } \\
\text { - tsunami mode: 2-min intervals, file-based } \\
\text { - permanent BGAN satellite receiving link, } \\
\text { transmitting on demand }\end{array}$ & $\begin{array}{l}1 / 30 \mathrm{~Hz}(1 \mathrm{~Hz} \text { in } \\
\text { tsunami mode })\end{array}$ \\
\hline GPS@buoy & $\begin{array}{l}\text { - GPS antenna/sea level height } \\
\text { measurements on ocean } \\
\text { - direct tsunami detection }\end{array}$ & $\begin{array}{l}\text { - normal mode: variable intervals, file-based } \\
\text { - tsunami mode: } 2 \text {-min intervals, file-based } \\
\text { - permanent BGAN satellite receiving link, } \\
\text { transmitting on demand }\end{array}$ & $1 / 3 \mathrm{~Hz}$ \\
\hline $\begin{array}{l}\text { GPS@ external site } \\
\text { (e.g., IGS, Champ) }\end{array}$ & $\begin{array}{l}\text { - ground motion detection } \\
\text { - external reference frame }\end{array}$ & $\begin{array}{l}\text { - file-based (15-min files) and/or } \\
\text { real-time data streaming } \\
\text { - download from assigned data servers (internet) }\end{array}$ & $1 \mathrm{~Hz}$ \\
\hline
\end{tabular}

series from these stations are updated at the warning centre in 5-min (normal mode) or 2-min intervals (tsunami mode) while coordinate time series from other GITEWS GPS sensors (see Sects. 2.2 and 2.3) can be updated in hourly intervals only. This allows a continuous ground motion tracking for GPS RTR locations and continuous information about the GPS RTR stations' availability. Strong incidents due to earthquakes and technical problems at the station or with the communication link should become visible very early.

The GPS RTR station design is based on a 19-inch rack mount construction housed in either a regular indoor rack (Fig. 2a) or weatherproof outdoor rack (Fig. 2b). Both racktypes have been tested in a climate chamber for proper operation in the expected range of ambient temperature and humidity. The outdoor rack is a double case construction that allows passive cooling (no fans) without ventilation holes in the inner walls (convection between inner and outer walls). The outdoor box was selected for installations where no building was available to shelter the electronics. It gives sufficient protection against the different weather conditions in Indonesia and also against small animals and insects. Electronic components are installed in service-friendly modules, connected through front side cables. Even off-the-shelf components have their own extra cases to allow easy replacement in case of a malfunction. A set of batteries is placed next to the rack and allows the system to operate for more than 2 days in the case of mains power failure. The outdoor rack is larger than the indoor rack since it also includes the batteries inside.

The GPS RTR stations are distributed over the main islands of Indonesia, mostly away from the coast. Most are collocated with seismological stations sharing a VSAT communication terminal. All station locations are hosted by (a)
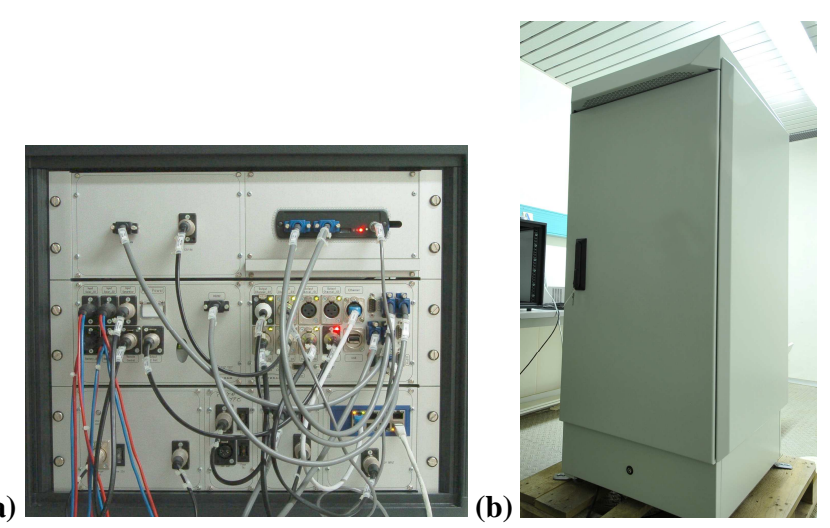

Fig. 2. Left: front of GPS RTR station; right: outdoor box with double walls and passive cooling.

BMKG (Indonesian Agency for Meteorology, Climatology and Geophysics), providing the locations with infrastructure and local support. The installation itself is supported by BAKOSURTANAL (National Coordinating Agency for Surveys and Mapping) which also maintains the GPS sensor station health monitoring and maintenance. A typical, deployed station setup is shown in Fig. 3 (installation at Maumere, Flores Island, Indonesia). The station is equipped with a VSAT antenna, a meteo sensor system, solar cell arrays for seismological power supply, a GPS choke ring antenna and a subsurface bunker (right side, only entrance lid visible below the chair) for the seismological equipment and the GPS receiver rack. The GPS antenna and the VSAT communication antenna are installed on separate steel masts moulded in reinforced concrete basements $(1 \mathrm{~m} \times 1 \mathrm{~m} \times 1 \mathrm{~m}$ each), which are expected to give sufficient ( $\mathrm{mm}$ level) stability. 


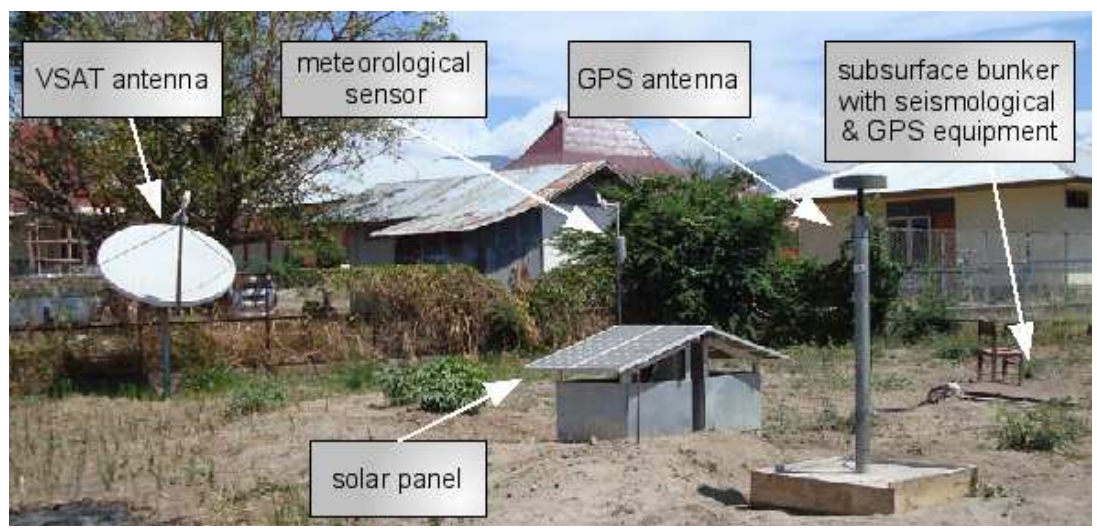

Fig. 3. GPS RTR station at Maumere, collocated with seismological instrumentation.

\subsection{GPS sensor stations at tide gauges}

These GPS sensors are collocated with tide gauge stations at coast line locations. The system design is similar to the GPS RTR station design using modular components (Schöne et al., 2008). GPS data are collected (beside tide gauge data) and locally stored at a rate of $1 \mathrm{~Hz}$. In normal mode the data are sent in configurable time intervals (e.g., some hours) over a BGAN satellite link, sampled down to $1 / 30 \mathrm{~Hz}$. There is a permanent BGAN receiving link at the station, in order to enable the reception of messages from the warning centre. If the tide gauge station receives a tsunami mode message from the warning centre, or detects a tsunami-like change of the local sea level, it immediately starts to send the most recent $1-\mathrm{Hz}$ data to the warning centre and enters a near real-time data transmission mode to transfer actual measurements. The near real-time data processing system at the warning centre then provides information on possible ground movements. This information can either be used to flag the collocated tide gauge measurements as being not useable (due to a vertical sensor station movement) or to correct the tide gauge data measurements with the detected sensor station movement values. If not being corrected or flagged invalid a vertical tide gauge station movement of a certain value may be misinterpreted as a sea level change of the same value (but in opposite direction).

\subsection{GPS sensors on buoys}

All GITEWS buoys (up to 10 buoys south off Sumatra and Java) carry a GPS sensor system. The idea is to detect, as soon as possible, a passing tsunami wave that causes a temporary sea level anomaly. Such an anomaly has a long period signature that allows the separation from normal sea waves with short period signatures as described in earlier works and demonstrated through experiments (Kato et al., 2000). The GITEWS buoys are anchored at deep sea locations and show changing coordinates and variable elevations. However, only the vertical component of the coordinates is of interest. Aux- iliary sensors for dipping and tilting are installed to apply corresponding corrections to the vertical component of the processed GPS data. Due to power supply constraints (solar cells), data from buoys are regularly sent via a BGAN satellite link in intervals of several hours only. The GPS data time resolution is $1 / 3 \mathrm{~Hz}$. After being switched to tsunami mode operation data still missing at the warning centre are sent immediately, followed by a period of near real-time data delivery. The GPS data are then processed at the warning centre in baseline mode, with at least one RTR station as reference. The buoy systems are switched to tsunami mode operation either by reception of a tsunami mode message from the warning centre (same principle as at the tide gauges) or by one of some special sensors on the ocean bottom. These special sensors, OBU (Ocean Bottom Unit) and PACT (Pressure based Acoustically Coupled Tsunami detector) measure, e.g., the hydrostatic pressure and send their data via an acoustic communication link to the buoy.

\section{Automatic near real-time GPS data processing}

GPS raw data from GITEWS GPS sensors with file-based data concepts (GPS at tide gauges and on buoys) are converted to RINEX version 2.11 (Receiver INdependent Exchange Format) using the TEQC software toolkit (Translation, Editing, and Quality Check). GPS data from GPS realtime reference stations is converted to the RTCM (Radio Technical Commission for Maritime Services) format using commercial Ntrip (Networked Transport of RTCM via Internet Protocol) caster software (Alberding $\mathrm{GmbH}$, Germany). The RTCM data is then converted to RINEX using Ntrip client software from BKG, Germany (Federal Agency for Cartography and Geodesy). The GITEWS GPS processing system uses the Bernese GPS software package 5.0 (Dach et al., 2007) as the kernel processor, with adaptations for near real-time processing. Coordinate time series are calculated in baseline mode (relative positioning) with doubledifferencing. As precise GPS satellite orbits from processing 


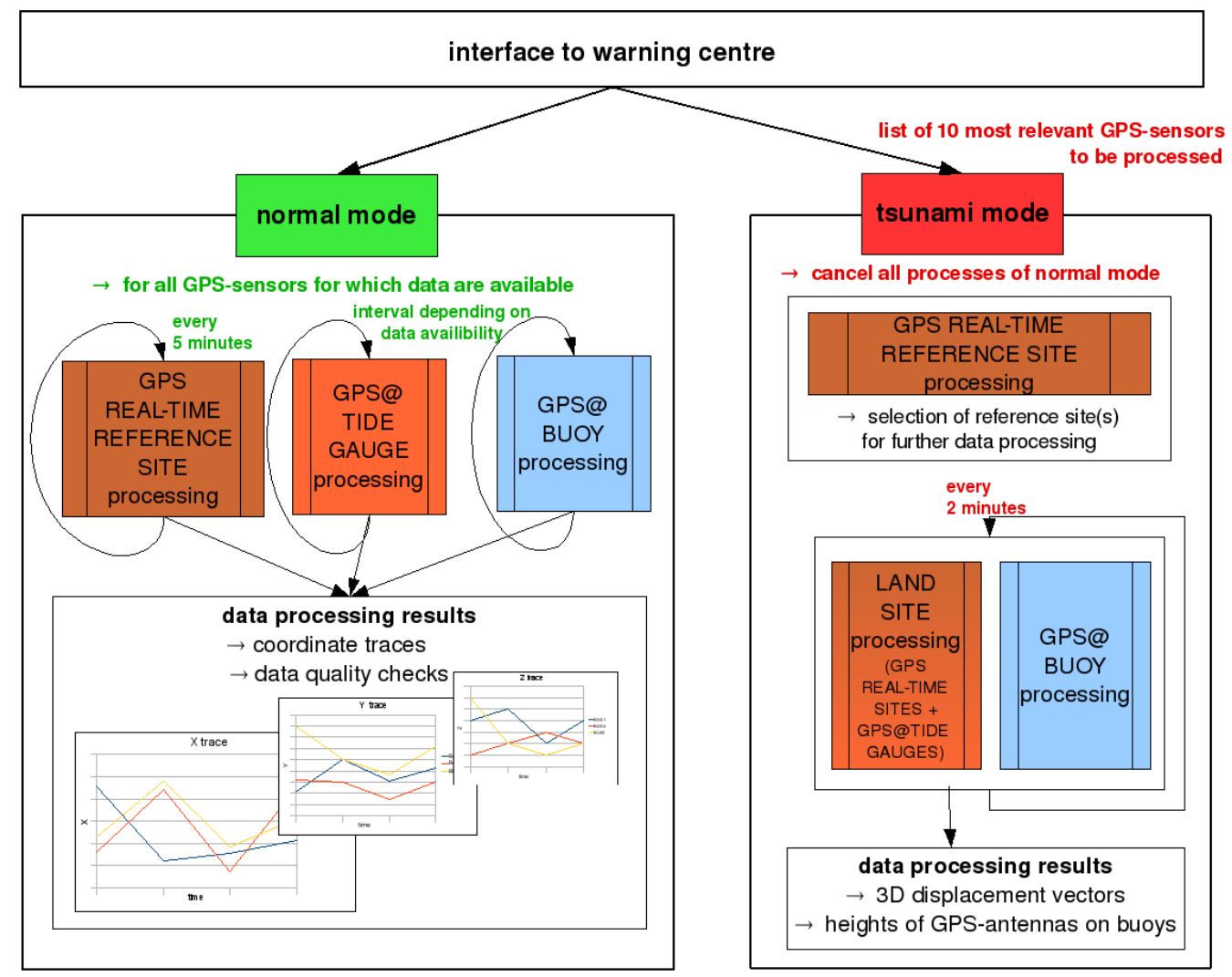

Fig. 4. GPS data processing in normal mode and tsunami mode.

centres (e.g., IGS) are not available with low latencies, the predicted part of ultra rapid orbits is used instead. In addition, GPS broadcast ephemeris data (transmitted by the GPS satellites) are received through the GPS RTR network stations. This less accurate orbit information is used only in case that ultra rapid orbit information is not accessible for any reason. There are different processing jobs for land station data and buoy data, which can be executed at the same time. The GPS processing system can be operated in two modes, the normal mode and the tsunami mode (as shown in Fig. 4).

\subsection{Normal mode GPS data processing}

In normal mode, all new data of all sensors are processed to allow a continuous sensor performance monitoring. As a result the system delivers processed data to the GPS GUI (Graphical User Interface) in order to display the GITEWS GPS network status. This task is not time critical and can be fulfilled, e.g., in 5-min intervals. Data from tide gauges and buoys are processed less often as these sensors send the data in flexible intervals (several hours) depending on local battery power and other constraints. At all times the GPS data processing system listens for a possible tsunami mode (pre-alert) message. These messages are generated by the DSS (Decision Support System) when a strong earthquake or another tsunami-relevant event has been detected. The messages are distributed over the TSB (Tsunami Service Bus), which supports the exchange of data and information between the warning centre system components (internal communication). If such a message is received by the GPS processing system, it cancels all normal processing activities and switches the GPS system to tsunami mode. There is no function to set a tsunami mode or alert by GPS-based components themselves. Such functionality could be added at a later time, triggered, e.g., by automatic detection of a sudden change of station coordinates.

\subsection{Tsunami mode GPS data processing}

The first step in tsunami mode, after immediate terminating all processes of the normal mode, is the processing of data from GPS real-time reference (RTR) stations. The raw data of these sensors are received continuously $(1 \mathrm{~Hz})$ in real-time and are therefore available without significant delay due to data transfers. Meanwhile GPS sensors at buoys and tide gauges are switched to near real-time data transmission and all available data retrieved. Then the system processes data of the 10 most relevant sensors, but in a 2-min interval. The corresponding list of most relevant sensors is determined by 


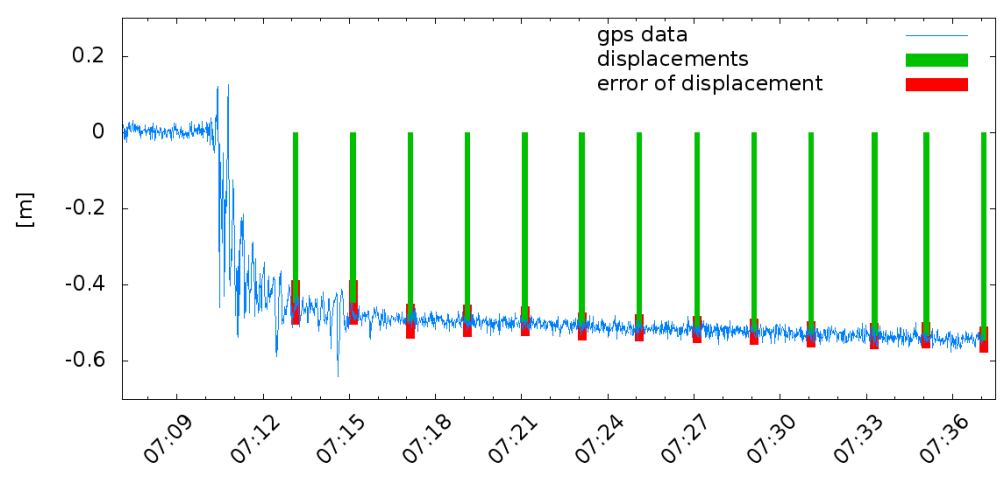

Fig. 5. Displacement determination from coordinate time series (up component only).

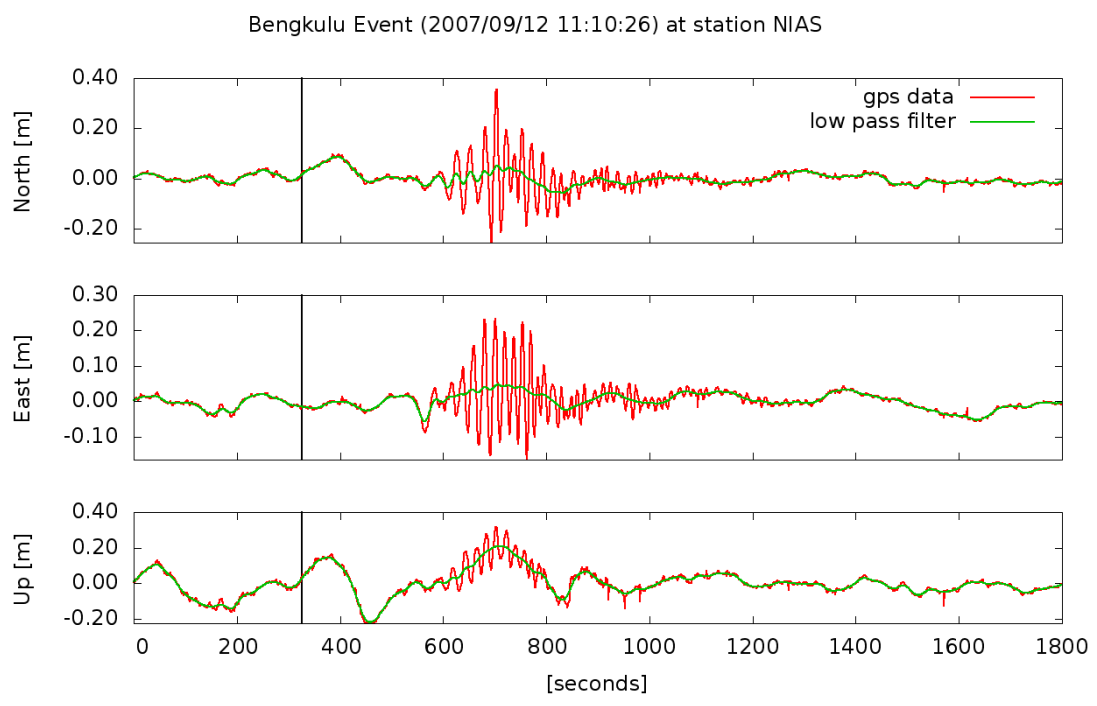

Fig. 6. Coordinate time series with seismic signal signatures, before and after filtering.

the DSS (e.g., stations located nearest to the earthquake focus) and provided over the TSB. The shorter time interval of $2 \mathrm{~min}$ is needed to keep the latency of the early warning results small while maintaining a high time resolution. The reason for having two processing modes is the limited computer capacity. It is not possible to process the high rate GPS data for all sensors over short time intervals.

\subsection{GPS data from onshore locations (ground tracking system)}

The mean coordinates based on the last processed GPS data (2-min windows of $1 \mathrm{~Hz}$ data) are compared with the mean coordinates of the same location over a 30-min time window, ending right before the earthquake occurrence time. This procedure is illustrated in Fig. 5 using a synthetic coordinate trace of unfiltered data (blue line, up component only). At about 07:10 h the blue line changes its mean level due to the simulated earthquake, being modulated with a seismic signal during the next minutes. Each green bar represents the difference between a 2-min processing interval and the initial coordinate component prior to the earthquake (zero level). These differences correspond to the observed land mass movements, also called displacements. The red bars at the bottom of the green bars show the calculated errors (calculated with variance propagation law) of the displacements (being higher when seismic signals are present). The mean error values are used as a measure of reliability and prevent the automatic product delivery (earthquake displacement values) if too high.

Real GPS data coordinate time series need to be filtered in advance of any automatic displacement determination as described above. The red lines in Fig. 6 show real processed GPS data $(1 \mathrm{~Hz})$, recorded at the GITEWS GPS station on Nias Island during a strong earthquake close to Bengkulu, Indonesia (12 September 2007, $M=8.4$ ). The time of the earthquake event is marked by the vertical lines. The noticeable high frequency signatures are due to ground movements caused by the earthquake. The distance in time to the earthquake event corresponds to the travel time of the seismic 
waves. These seismic signals might be an important source for future applications (GPS seismology). However, the example shows no persistent displacements after the time of seismic signal reduction. In order not to misinterpret seismic signatures as displacements these signals need to be suppressed. Low pass filtering of the example data results in the smoother green lines, giving a much better basis for detection of real displacements.

The displacement values (one value for $2 \mathrm{~min}$, representing 120 samples at $1 \mathrm{~Hz}$ ) are the final GPS processing result for land-based GPS sensors. They are delivered immediately and without any operator interpretation to the warning centre GTS (Ground Tracking System) display and decision supporting systems, e.g., to flag tide gauge data as described in Sect. 2.2. The displacement values are also and most advantageous used by the GITEWS SIM (simulation) module. This module selects the most probable tsunami scenario from some thousands of pre-calculated scenarios, based on a matching process with all available, different sensor system measurements (Behrens et al., 2008).

\subsection{GPS data from offshore locations}

GPS data sets from buoys are processed in baseline mode with GPS RTR stations as reference. Figure 7 is an example covering approximately 1.5 days of processed GPS data from a buoy. The red line (coordinate time series of vertical component, values between $-12.5 \mathrm{~m}$ and $-17.5 \mathrm{~m}$ ) represents the final product of the GPS processing. It is the instant height of the GPS antenna, which does not yet fully correspond to the sea level height. Some corrections provided by dedicated sensors, e.g., due to tilting and dipping of the buoy still need to be applied. The processing from antenna height to sea level height is not part of the GPS data processing system. It is part of the oceanographic (buoy) data processing system and not subject of this paper.

However, an estimation of the GPS data processing quality (without corrections as mentioned above) can be achieved through the use of a low pass filter in order to suppress the high frequency signals coming from normal ocean waves and buoy movements. The green line represents the same data as the red line, but low pass filtered. The tidal frequency is clearly visible. A comparison with data from a normal tide model as reference (blue line) shows a good agreement.

\section{GPS data processing system GUI (graphical user interface)}

A new graphical user interface for the GPS processing and network monitoring was developed and installed at the tsunami warning centre in Jakarta. The GUI supports both, a quick view for all staff members at the warning centre ( $24 \mathrm{~h} / 7 \mathrm{~d}$ operation) as well as more thorough analysis. It is web-based and allows a flexible and user selectable arrange-

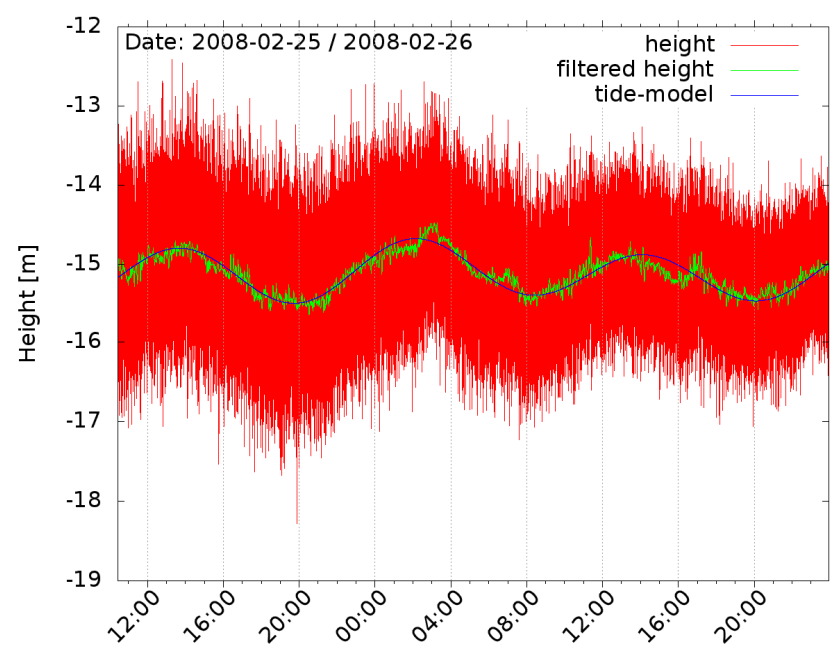

Fig. 7. Processed data from a GPS sensor on a buoy (red), filtered (green) and a tide model (blue).

ment of individual frames as well as being viewed at remote locations outside the warning centre. This part of the concept supports the dialogue between warning centre staff on duty or on standby and sensor station maintenance staff. Figure 8 shows a screenshot (taken from the developing system at the GFZ in Potsdam) of the "processing view" screen as one example of the new GUI pages. It shows details about the status (e.g., which types of orbit information are available) and the progress of the GPS data processing (current processing steps etc.) and if there were any problems during previous processing times. Although not needed for the processing itself, this view is important for operators to confirm a proper system function, especially in case of a tsunami pre-alert.

Another view gives a network status overview on a moveable map (similar to Fig. 1) with zoom functions. Symbols indicate the different sensor station types and states (GPS real-time reference, GPS at tide gauge or buoy and other stations). The health status of each GPS station is colourcoded (green, yellow and red). Special symbols are displayed if there is no connection to a station due to communication problems or if a sensor power supply or battery voltage has dropped below a critical level. The status over time ( $24 \mathrm{~h})$ is displayed by a GUI page with one horizontal bar for each station. It has an automatic update function, but can also be shifted on the time scale, which allows inspection of network station performance in the past. A mouse click on a particular station performance bar at a particular point of time opens a popup window displaying the corresponding station data for detailed analysis. There are more views available, e.g., for coordinate time series traces and quality check parameters and with individual station information, such as local contacts and infrastructure including pictures of the sites. 


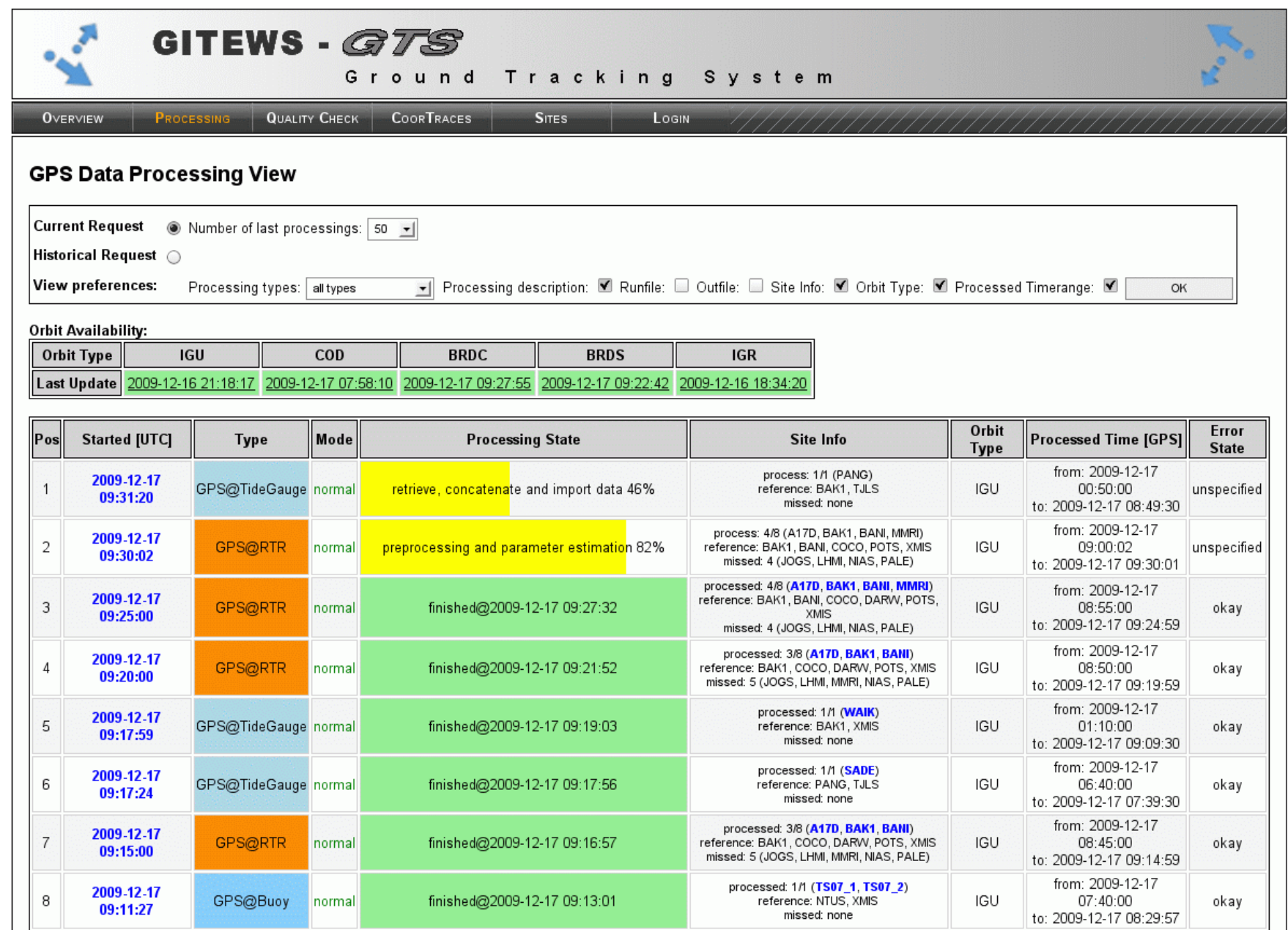

Fig. 8. Screenshot of GPS data processing view.

\section{Summary and outlook}

A GPS-based tsunami early warning component, developed by GFZ within the GITEWS project, was installed in Indonesia. The system provides measurements of land mass movements due to earthquakes and coordinates of GPS sensors on buoys, corresponding to sea levels. It supports the prediction of a tsunami using GPS data from land and the detection and confirmation of a tsunami with offshore-measured data at the earliest possible time. In addition, the data can be used to improve the reliability of tide gauge data by confirming that a tide gauge location has not moved during an earthquake. The provision of all this information is expected to significantly increase the reliability of tsunami early warnings. Test installations of single frequency receivers close to 2 frequency receiver locations are planned as well as the instal- lation of more BGAN modems (less tight antenna pointing requirements than for VSAT). This will further increase the system reliability, which is most important for early warning applications. A function for a tsunami pre-alert, released due to automatically detected displacements measured by GPS, may be added at a later time.

Acknowledgements. The GITEWS project (German Indonesian Tsunami Early Warning System) is carried out through a large group of scientists and engineers from different German research institutes under the leadership of the GFZ, German Research Centre for Geosciences. Funding is provided by the German Federal Ministry for Education and Research (BMBF), Grant 03TSU01.

Edited by: U. Münch

Reviewed by: P. H. Denys and two other anonymous referees 


\section{References}

Behrens, J., Klaschka, F., Mentrup, L., Raape, U., Strobl, C., Tessmann, S., and Riedlinger, T.: Handling Uncertainty in Tsunami Early Warning: Interaction between Decision Support and MultiSensor Simulation System, Proceedings of the International Conference on Tsunami Warning (ICTW), Bali, Indonesia, 2008.

Dach, R., Hugentobler, U., Fridez, P., and Meindl, M.: Bernese GPS Software 5.0., Astronomical Institute, University of Bern, 2007.

Kato, T., Terada, Y., Kinoshita, M., Kakimoto, H., Isshiki, H., Matsuishi, M., Yokoyama, A., and Tanno, T.: Real-time observation of tsunami by RTK-GPS, Earth Planets Space, 52, 841-845, 2000.

Meinig, C., Stalin, S. E., Nakamura, A. I., and Milburn, H. B.: RealTime Deep-Ocean Tsunami Measuring, Monitoring, and Reporting System: The NOAA DART II Description and Disclosure, 2005.

Rudloff, A., Lauterjung, J., Münch, U., and Tinti, S.: Preface "The GITEWS Project (German-Indonesian Tsunami Early Warning System)", Nat. Hazards Earth Syst. Sci., 9, 1381-1382, 2009, http://www.nat-hazards-earth-syst-sci.net/9/1381/2009/.
Schöne, T., Subarya, C., Manurung, P., Nölte, C., Roemer, S., Galas, R., Illigner, J., Kloth, A., Köppl, M., Queisser, T., Selke, C., Stolarczuk, N., and Bartsch, M.: Offshore And Onshore Sea Level Measurements, Proceedings of the International Conference on Tsunami Warning (ICTW), Bali, Indonesia, 2008.

Sobolev, S. V., Babeyko, A. Y., Wang, R., Hoechner, A., Galas, R., Rothacher, M., Sein, D. V., Schröter, J., Lauterjung, J., and Subarya, C.: Tsunami early warning using GPS-Shield arrays, J. Geophys. Res., 112, B08415, doi:10.1029/2006JB004640, 2007.

Subarya, C., Chlieh, M., Prawirodirdjo, L., Avouac, J., Bock, Y., Sieh, K., Meltzner, A., Natawidjaja, D., and McCaffrey, R.: Plate-boundary deformation associated with the great SumatraAndaman earthquake, Nature, 440, 46-51, 2006.

Wilson, P. and Michel, G. W. (Eds.): The GEODYnamics of S and SE Asia (GEODYSSEA) Project, Scientific Technical Report STR 98/14, Geoforschungszentrum Potsdam, Commission of the European Community, EC contract CI1*CT93-0337, 1998. 